\title{
A Randomized, Controlled Trial Comparing the Impact of a Low-Calorie Ketogenic vs a Standard Low-Calorie Diet on Fat-Free Mass in Patients Receiving an Elipse ${ }^{\mathrm{TM}}$ Intragastric Balloon Treatment
}

\author{
Luigi Schiavo $^{1,2}$ (1) Giovanni De Stefano ${ }^{3}$. Francesco Persico ${ }^{4}$. Stefano Gargiulo ${ }^{5}$. Federica Di Spirito ${ }^{1}$. \\ Giulia Griguolo $^{1}$ - Niccolò Petrucciani ${ }^{6}$ - Eric Fontas ${ }^{7}$ - Antonio lannelli ${ }^{6,8,9} \cdot$ Vincenzo Pilone $^{1,2}$
}

Received: 27 April 2020 / Revised: 5 November 2020 / Accepted: 10 November 2020 / Published online: 20 November 2020

(C) The Author(s) 2020

\begin{abstract}
Background The Elipse ${ }^{\mathrm{TM}}$ intragastric balloon (EIGB) is a new swallowable balloon for weight loss (WL). Preserving metabolically active fat-free mass (FFM) and resting metabolic rate (RMR) during WL are crucial to maximize fat mass (FM) loss. After EIGB placement, a standard low-calorie diet (LCD) is generally prescribed. A low-calorie ketogenic diet (LCKD) has proven to be safe and effective in reducing FM while preserving FFM and RMR.

Objective To prospectively compare the effects on WL, FM, FFM, and RMR in two groups of patients who were randomized to two different diets: LCKD and a standard LCD after EIGB placement.

Methods WL, FM, FFM, and RMR were measured before EIGB and at 4 months in 48 patients who received either a LCKD $(n=24)$ or a standard LCD $(n=24)$. Compliance in following the prescribed diet was determined with food frequency questionnaires in all patients. The impact of LCKD and LCD on renal function was also evaluated.

Results The LCKD group showed a significantly lower decrease in FFM and RMR when compared with the LCD group (3.55 vs $14.3 \%, p<0.001 ; 9.79$ vs $11.4 \%, p<0.001$, respectively). FM decreased more significantly with LCKD compared to LCD (41.6 vs $33.1 \%, p=0.0606$ ). Compliance in following the prescribed diets, without negative impact on renal function, was found.
\end{abstract}

Luigi Schiavo

1schiavo@unisa.it

Giovanni De Stefano

gdestefano@meditamedical.it

Francesco Persico

francescopersico@hotmail.it

Stefano Gargiulo

stefgar.doc4@gmail.com

Federica Di Spirito

f.dispirito@unisa.it

Giulia Griguolo

g.griguolo@unisa.it

Niccolò Petrucciani

niccolo.petrucciani@uniroma1.it

Eric Fontas

fontas.e@chu-nice.fr

Antonio Iannelli

iannelli.a@chu-nice.fr
Vincenzo Pilone

vpilone@unisa.it

1 Department of Medicine, Surgery, and Dentistry, "Scuola Medica Salernitana", University of Salerno, Fisciano, SA, Italy

2 Center of Excellence of Bariatric Surgery of the Italian Society of Obesity Surgery and Metabolic Disease (SICOB), Unit of General and Emergency Surgery, University Hospital San Giovanni di Dio e Ruggi d'Aragona, Mercato San Severino, Salerno, Italy

3 Med.Ita Advanced Biomedical Solutions, Naples, Italy

4 Unit of General and Specialistic Surgery, A.O.R.N. dei Colli Ospedali Monaldi-Cotugno-CTO, Naples, Italy

5 General Surgery Unit, Santa Maria La Bruna Clinic, Torre del Greco, Italy

6 Digestive Unit, Archet 2 Hospital, University Hospital of Nice, F-06202 Nice, France

7 Direction de la Recherche Clinique, University Hospital, Nice, France

8 Inserm, U1065, Team 8 "Hepatic Complications of Obesity", F-06204 Nice, France

9 University of Nice Sophia-Antipolis, F-06107 Nice, France 
Conclusion Based on our findings, despite the small sample size, we were able to support the hypothesis that LCKD is associated with an increased FM loss while reducing the FFM loss and the RMR, without interfering with renal function after EIGB.

Keywords Obesity $\cdot$ Elipse $\mathrm{TM}^{\mathrm{TM}}$ intragastric balloon $\cdot$ Fat-free mass $\cdot$ Resting metabolic rate $\cdot$ Low-calorie ketogenic diet

\section{Introduction}

Intragastric balloons have been used for weight loss (WL) in the last two decades, but the need for hospital recovery, upper GI endoscopy, and anesthesia is major limitations for this technique. The Elipse ${ }^{\mathrm{TM}}$ intragastric balloon (EIGB) is a new swallowable balloon that has no such limitations and has been proven to be safe, effective in achieving weight loss is also, and well tolerated by patients [1-6].

After EIGB placement, a standard low-calorie diet (LCD) program, based on a daily intake of about $1000-1200 \mathrm{kcal} /$ day, is generally prescribed [6]. The combination of the restrictive effect of EIGB and diet accounts for a significant loss of fatty free mass (FFM). Indeed, maintaining adequate FFM is an important consideration when making WL because muscles play a central role in whole-body protein metabolism [7]. Additionally, a significant decrease in FFM may negatively affect the resting metabolic rate (RMR) [8-11], slow the rate of WL, and predispose to weight regain [12]. Moreover, no studies have been conducted so far on the amount of WL attributed to the loss of fat mass (FM) and FFM in the setting of EIGB treatment.

A low-calorie ketogenic diet (LCKD) has been proven to be safe and effective for WL [13-17], especially in reducing FM while preserving FFM and RMR [18-20].

Therefore, we designed a randomized controlled trial to compare the effect of LCKD and a standard LCD after EIGB on WL, FM, FFM, and RMR.

\section{Materials and Methods}

\section{The Elipse ${ }^{\mathrm{TM}}$ Intragastric Balloon System}

The EIGB (Allurion Technologies, Natick, MA, USA) is a swallowed, self-emptying, and excreted gastric balloon for WL [21]. It is folded into a vegetarian capsule and attached to a thin catheter. The capsule is easily swollen with a glass of water. However, in case swallowing is problematic, a stylet can be fed through the catheter to stiffen it, allowing the physician to gently push the capsule during swallowing. The EIGB contains a small radiopaque ring that can be used to confirm its correct position inside the stomach through an abdominal X-ray [21]. Once the capsule is in the stomach, the balloon is filled with $550 \mathrm{~mL}$ of liquid consisting distilled water with potassium sorbate preservative, and then the catheter is removed, and a second X-ray is performed to confirm the balloon is filled and that the placement is complete [21]. After approximately 4 months, a time-activated release valve opens, allowing the balloon to empty and pass naturally through the digestive system to be excreted and thus ideally does not require any endoscopic procedure [22].

\section{Pre- and Post-EIGB Placement Medical Treatment}

Patients fasted for at least $8 \mathrm{~h}$ prior to the EIGB placement and were given proton pump inhibitors, anti-emetics, and antinausea and vomiting drugs before and after the EIGB placement. Details are reported in Table 1.

\section{Study Design and Patient Selection}

Between 2018 and 2019, we conducted a pilot, prospective, randomized, controlled trial on a cohort of consecutive obese individuals undergoing EIGB at our institutions. In accordance with other studies, the EIGB inclusion criteria were as follows: body mass index $(\mathrm{BMI}) \geq 27 \mathrm{~kg} / \mathrm{m}^{2}$, and less than $45 \mathrm{~kg} / \mathrm{m}^{2}$, and age between 18 and 65 years. Exclusion criteria included previous bariatric or gastric surgery, bowel obstruction, hiatal hernia $>5 \mathrm{~cm}$, heart failure, blood coagulation disorders, more than one other abdominal/ gynecological operation, certified pregnancy, eating disorders (bulimia, binge eating disorder, or night eating syndrome) [1-6], serum creatinine level greater than $1.8 \mathrm{mg} /$ $\mathrm{dL}$ or liver enzyme (glutamic oxaloacetic transaminase (GOT) or glutamic pyruvic transaminase (GPT)) levels less than three times the upper limit of normal [17], inability to comply with the LCKD or LCD for religious reasons, or the presence of chewing or swallowing disorders. After EIGB placement, the patients were randomized into two groups: the LCKD group that followed a LCKD and the LCD group that followed a standard LCD. Considering the small sample size, to achieve balance in the allocation of patients to treatment arms and to increase the probability that each arm contained an equal number of patients, block randomization was used [23]. Informed written consent was obtained from each participant after being informed about the purpose and nature of the study (Research Registry Unique Identifying Number 5478). 
Table 1 Medical Therapy before and after the EIGB placement

\begin{tabular}{|c|c|}
\hline Medicaments & Timing \\
\hline $\begin{array}{l}\text { Pantoprazole (Pantorc } ®) ~(40 \mathrm{mg}) \\
\quad \text { (Administered per os) }\end{array}$ & 7 days prior the EIGB placement and through the end of the balloon treatment (4 months) \\
\hline $\begin{array}{l}\text { Aprepitant }(\text { Emend®) }(125 \mathrm{mg}) \\
\quad \text { (Administered per os) }\end{array}$ & The evening before the EIGB placement and then for 3 consecutive days after the balloon placement \\
\hline $\begin{array}{l}\text { Ondansetron (Zofran®) }(8 \mathrm{mg}) \\
\quad \text { (Administered per os) }\end{array}$ & $\begin{array}{l}2 \mathrm{~h} \text { prior the EIGB placement; } 6 \mathrm{~h} \text { after the balloon placement, and then for } 3 \text { consecutive days after the } \\
\text { EIGB treatment }\end{array}$ \\
\hline
\end{tabular}

\section{Primary and Secondary Outcomes}

The primary outcome was the amount of FFM loss. Secondary outcomes included body weight (BW), FM, RMR, and dietary compliance.

\section{LCKD and LCD Characteristics}

Patients were discharged 2-4 h after the EIGB placement. With regard to the dietary recommendations, only fluid hydration was permitted for the first $24 \mathrm{~h}$. During the first week, a gradual progression to a semi-liquid diet (yogurt, mashed potatoes, thin soup, and puréed vegetables) was recommended in both groups. At the beginning of the second-week post-EIGB placement, the patient proceeded with caution to a hypocaloric, textured diet plan. Regular and moderate physical activity was suggested to all patients $\left(30 \mathrm{~min}^{\text {day }}{ }^{-1}\right)$. At this time, patients enrolled for the study were randomized in two groups: a LCKD group (experimental group) and a standard LCD group (control group). Both regimens were applied until the end of the treatment after a detailed discussion on both diet schemes with the nutritionist. To ensure that all included patients consumed a similar diet, we developed two meal plans (LCKD and LCD), assigning a specific quantity to individual foods using a free online keto diet application (https://www.eatthismuch.com) and the Nutrigeo 8 software (Progeo, Ascoli Piceno, Italy) for the LCKD plan and the LCD plan, respectively.

The macronutrients composition of the LCD and LCKD was $40 \%$ carbohydrates, $43 \%$ proteins, and $15 \%$ fats $(\sim$ $1200 \mathrm{kcal} /$ day) [24], and 4\% carbohydrates, $25 \%$ proteins, and $71 \%$ fats $(\sim 1200 \mathrm{kcal} /$ day $)$ [17], respectively. An example of the LCKD and LCD daily plan is reported in Fig. 1.

\section{BW, FM, FFM, RMR, and Laboratory Determinations}

The details regarding the sequence of measurements are shown in Fig. 2. BW $(\mathrm{kg})$ and height $(\mathrm{cm})$ were determined under standard conditions. Height was measured using a Seca 206 mechanical measuring tape (Intermed, Milano, Italy); BW were assesed by the Seca 869 flat digital scale (capacity 250 $\mathrm{Kg}$, Intermed, Milano, Italy). Patients' body composition was measured by bioelectrical impedance assay (BIA) using the
Jawon IOI 353 Segmental Body Composition Monitor (Cosmed, Italy) [9, 11, 17]. The instrument used is the last generation in body composition analysis, using the latest multi-frequency technology, and it is in compliance with the requirements of the Directive 90/384/EEC for weighing with non-automatic devices in the medical sector and the Directive 93/42/EEC for medical devices. To perform an appropriate analysis, as we previously reported [8, 9, 11, 16, 25], all patients were required to comply with these conditions prior to the BIA: no food ingestion for at least $4 \mathrm{~h}$, minimal intake of $2 \mathrm{~L}$ of water the day before, no physical activity for at least $8 \mathrm{~h}$, no coffee or alcoholic beverage consumption during at least $12 \mathrm{~h}$, and no diuretic use for at least $24 \mathrm{~h}$. Patients were also asked to empty their bladder immediately prior to the BIA test. Patient's RMR were measured by indirect calorimetry using Fitmat PRO monitor (Cosmed, Italy) [11, 17]. Examinations were performed from 8:00 to 10:00 a.m. in the same room under thermos neutral conditions, in order to reduce diurnal variation between subjects [26-29]. Measurements were performed at a duration of $15 \mathrm{~min}$ following a prior 5-10-min test.

Blood tests included liver enzymes (GOT, GPT, and gamma-glutamyl transferase (GGT)), glucose, insulin, creatinine, urea, and glomerular filtration rate (GFR), uric acid, urea nitrogen, ketonemia, iron, hemoglobin, total cholesterol, high-density lipoprotein (HDL), low-density lipoprotein (LDL), and triglycerides. The GFR was calculated using the Modification of Diet in Renal Disease formula [30]. All blood analyses were performed in an approved laboratory with internal and external quality controls using the reagents provided by the manufacturer and following the manufacturer's instructions. Data were compared with accepted clinical cutoff values (Table 2).

\section{Dietary Compliance Assessment Methods}

Nutritional assessment and dietary counseling were scheduled at 1, 2, 3, and 4 months after EIGB placement (Fig. 2). Dietary assessments were primarily performed using questionnaires (3-day estimated food records and 72-h recalls) [31-33]. Nutrient intakes were calculated from the 72-h recalls and 3day dietary records (Sunday to Tuesday; breakfast to bedtime) using the Nutrigeo 8 software. 


\section{LCKD (1200 kcal/day)}

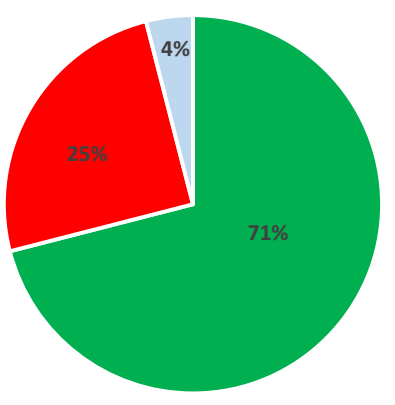

- Fats - Proteins $\backsim$ Carbs
Breakfast: Eggs (150 g), Olive oil (5 g)

Snack: Pecans $(30 \mathrm{~g})$

Lunch: Lamb loin (250 g), Asparagus (250 g), olive oil (10gr)

Snack: Cheddar cheese ( $30 \mathrm{~g})$

Dinner: Tuna (250 g), Lettuce (250 g), olive oil (10gr)
LCD (1200 kcal/day)

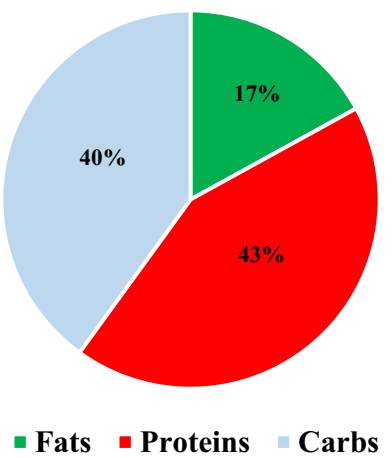

Breakfast: $300 \mathrm{ml}$ low-fat milk with 4.5 scoops of cereals.

Snack: 225 yogurt (natural or fruit) $0.1 \%$ of fats

Lunch: Lunch Vegetable soup (optional) with $225 \mathrm{~g}$ of beef with vegetables and $45 \mathrm{~g}$ bread

Snack: 1 fruit $(150 \mathrm{~g})$

Dinner: Dinner Vegetable soup (optional) with $300 \mathrm{~g}$ of tuna with vegetables and $45 \mathrm{~g}$ bread

Fig. 1 Sample $1200 \mathrm{kcal}$ intervention daily menu for low-calorie ketogenic diet (LCKD) and low-calorie diet (LCD) group

\section{Statistics}

\section{Sample Size Calculation and Statistical Analysis}

Based on our previous investigations (personal unpublished data) and literature review, we made the hypothesis that patients in the LCD would lose $10( \pm 3) \mathrm{kg}$ of FFM and those in the experimental group (LCKD), only $7 \mathrm{~kg}$. Using a priori power analysis (G*Power Software, Dusseldorf, Germany), we found that a sample of 21 patients in each arm could detect a difference in the primary outcome between the groups, with $90 \%$ power and an alpha error of $5 \%$. We planned to include 24 patients per group considering $15 \%$ drop out.

The effects of post-EIGB placement LCKD and LCD diet program were directly compared by using the paired sample $t$-test for continuous variables for comparison within groups and the Mann-Whitney test for comparison between LCKD

\begin{tabular}{|c|c|c|c|c|c|}
\hline Measurement & $\begin{array}{l}\text { Before EIGB } \\
\text { placement }\end{array}$ & $\begin{array}{l}\text { 1-month } \\
\text { follow-up }\end{array}$ & $\begin{array}{l}\text { 2-months } \\
\text { follow-up }\end{array}$ & $\begin{array}{l}\text { 3-months } \\
\text { follow-up } \\
\mid\end{array}$ & $\begin{array}{l}\text { 4-months } \\
\text { follow-up }\end{array}$ \\
\hline BLOOD & & & & & \\
\hline BW & & & & & \\
\hline FM & & & & & \\
\hline FFM & & & & & \\
\hline RMR & & & & & \\
\hline 3-DAY RECORD & & & & & \\
\hline 2-HOUR RECALL & & & & & \\
\hline
\end{tabular}

Fig. 2 Time periods of blood sampling, body weight (BW), fat mass (FM), fat-free mass (FFM), resting metabolic rate (RMR), 3-day record, and 72-h recall during the Elipse ${ }^{\mathrm{TM}}$ intragastric balloon (EIGB) treatment 
Table 2 Patients' clinical parameters before EIGB placement and after 4 months follow-up

\begin{tabular}{|c|c|c|c|c|}
\hline Clinical parameters & Diet & Pre-EIGB placement & Post-EIGB (follow-up 4 months) & $p$ value \\
\hline \multirow[t]{2}{*}{ Triglycerides $(\mathrm{mg} / \mathrm{dL})[\leq 230]$} & LCKD & $220 \pm 36$ & $114 \pm 15.2$ & $<0.001 *$ \\
\hline & LCD & $202 \pm 21.2$ & $93 \pm 8.3$ & $<0.001 *$ \\
\hline \multirow[t]{2}{*}{ Total cholesterol $(\mathrm{mg} / \mathrm{dL})[<200]$} & LCKD & $226 \pm 15.6$ & $164 \pm 43.4$ & $<0.001 *$ \\
\hline & LCD & $210 \pm 27.4$ & $135 \pm 27.5$ & $<0.001 *$ \\
\hline \multirow[t]{2}{*}{$\mathrm{HDL}(\mathrm{mg} / \mathrm{dL})[30-70]$} & LCKD & $38.5 \pm 7.6$ & $71 \pm 8.3$ & $<0.001 *$ \\
\hline & LCD & $33.8 \pm 8.3$ & $83 \pm 6.5$ & $<0.001 *$ \\
\hline \multirow[t]{2}{*}{$\mathrm{LDL}(\mathrm{mg} / \mathrm{dL})[<150]$} & LCKD & $147 \pm 25.3$ & $78.2 \pm 11.4$ & $<0.001 *$ \\
\hline & LCD & $138 \pm 26.2$ & $41.4 \pm 17.9$ & $<0.001^{*}$ \\
\hline \multirow[t]{2}{*}{ Glucose (mg/dL) [65-110] } & LCKD & $123 \pm 10.2$ & $82 \pm 18.9$ & $<0.001 *$ \\
\hline & LCD & $130 \pm 24.7$ & $92 \pm 26.9$ & $<0.001 *$ \\
\hline \multirow[t]{2}{*}{ Insulin $(\mathrm{mU} / \mathrm{L})[<25]$} & LCKD & $11.4 \pm 7.9$ & $4.3 \pm 1.9$ & $<0.001 *$ \\
\hline & LCD & $8.9 \pm 5.4$ & $5.3 \pm 2.3$ & $<0.001 *$ \\
\hline \multirow[t]{2}{*}{ GOT (U/L) [10-59] } & LCKD & $50 \pm 8.1$ & $24 \pm 10.4$ & $<0.001 *$ \\
\hline & LCD & $40 \pm 9.9$ & $26 \pm 7.4$ & $<0.001 *$ \\
\hline \multirow[t]{2}{*}{ GPT (U/L) [0-50] } & LCKD & $41 \pm 10.3$ & $28 \pm 11.2$ & $<0.001 *$ \\
\hline & $\mathrm{LCD}$ & $37 \pm 8.3$ & $22 \pm 8.9$ & $<0.001 *$ \\
\hline \multirow[t]{2}{*}{ GGT (U/L) [10-50] } & LCKD & $28 \pm 16.2$ & $14 \pm 3.4$ & $<0.001 *$ \\
\hline & $\mathrm{LCD}$ & $29 \pm 9.8$ & $22 \pm 6.7$ & $<0.001 *$ \\
\hline \multirow[t]{2}{*}{ Creatinine (mg/dL) [0.5-1.3] } & LCKD & $1.15 \pm 0.5$ & $0.92 \pm 1.2$ & $0.391 * *$ \\
\hline & $\mathrm{LCD}$ & $0.94 \pm 0.3$ & $1.12 \pm 1.4$ & $0.541 * *$ \\
\hline \multirow[t]{2}{*}{ Uric acid $(\mathrm{mg} / \mathrm{dL})[2.4-7]$} & LCKD & $5.4 \pm 2.5$ & $4.60 \pm 3.2$ & $0.339 * *$ \\
\hline & LCD & $5.9 \pm 2.9$ & $6.3 \pm 2.4$ & $0.605^{* *}$ \\
\hline \multirow{2}{*}{$\begin{array}{l}\text { Urea nitrogen }(\mathrm{mg} / \mathrm{dL}) \\
\quad[5 \text { to } 20]\end{array}$} & LCKD & $19 \pm 8.2$ & $16 \pm 8.4$ & $0.217 * *$ \\
\hline & LCD & $17 \pm 7.2$ & $19 \pm 7.6$ & $0.354 * *$ \\
\hline \multirow[t]{2}{*}{ Ketonemia $(\mathrm{mmol} / \mathrm{L})[0-0.6]$} & LCKD & $0.02 \pm 0.03$ & $0.18 \pm 0.2$ & $<0.001 *$ \\
\hline & LCD & $0.04 \pm 0.02$ & $0.047 \pm 0.05$ & $0.527 * *$ \\
\hline \multirow[t]{2}{*}{ Iron (ng/dL) [65-175] } & LCKD & $96 \pm 16.2$ & $93 \pm 13.4$ & $<0.488^{* *}$ \\
\hline & LCD & $85 \pm 11.4$ & $79 \pm 11.7$ & $<0.0785^{* *}$ \\
\hline \multirow[t]{2}{*}{$\mathrm{Hb}(\mathrm{g} / \mathrm{dL})[12.5-18]$} & LCKD & $13.4 \pm 4.5$ & $12.7 \pm 5.4$ & $0.627 * *$ \\
\hline & LCD & $14.6 \pm 6.9$ & $12.5 \pm 7.8$ & $0.328^{* *}$ \\
\hline
\end{tabular}

EIGB, Elipse intragastric balloon

LCKD, low-calorie ketogenic diet

LCD, low-calorie diet

HDL, high-density lipoprotein

LDL, low-density lipoprotein

GOT, glutamic oxaloacetic transaminase

GPT, glutamic pyruvic transaminase

GGT, gamma-glutamyl transferase

$\mathrm{Hb}$, hemoglobin

$* p<0.05) ; * * p \geq 0.05$

and LCD groups. The pattern of BW, FM, FFM, and RMR changes during the period study was expressed as a percentage and plotted over time. Nutrient intake comparison between the prescribed diets, the 3-day estimated food records, and the 72-h recalls were performed by analysis of variance (ANOVA). Block randomization was performed using a free online Graph Pad Quick Calcs Software (https://www.graphpad.com/quickcalcs/ randomize1/). Data are reported as mean \pm standard deviation (SD). A $p$ value $<0.05$ was considered statistically significant. Furthermore, any $p$ value less than 0.001 was conventionally stated merely as $p<0$. 
001. IBM SPSS Statistics for Windows (Version 25.0. Armonk, NY: IBM Corp) was used for statistics.

\section{Results}

\section{Characteristics of the Study Population}

Figure 3 reports the flow chart of patient's selection. Of 122 consecutive patients (64 females, 58 males), 48 (26 females, 22 males) met the inclusion criteria and accepted to join the study whereas $74(36 \mathrm{M}, 38 \mathrm{~F})$ did not (Fig. 3).

Pre-EIGB placement mean age and BMI were $39 \pm$ 8.8 years and $37.8 \pm 4.9 \mathrm{~kg} / \mathrm{m}^{2}$ in the LCKD group, and 41 \pm 4.3 years and $37.2 \pm 6.4 \mathrm{~kg} / \mathrm{m}^{2}$ for the LCD group, respectively. Before EIGB placement, LCKD and LCD groups were comparable in terms of BW, FM, and FFM ( $p=$ $0.227,0.496$, and 0.463 , respectively) whereas RMR was significantly higher in the LCKD group $(p=0.0232)$ (Table 3). No patients dropped out the study. As expected, we observed that BW, FM, FFM, and RMR significantly decreased after 4 months follow-up in both groups (LCKD $(p<0.001, p<0.001, p=0.0260$, and $p<0.001$, respectively) and $\operatorname{LCD}(p<0.001, p<0.001, p=0.0232$, and $p<0.001$, respectively)) (Table 3 ).

\section{Performance, Safety, and Side Effects}

93.7\% of patients (45/48) swallowed the Elipse ${ }^{\mathrm{TM}}$ capsule with a glass of water, whereas three patients $(6.3 \%)$ required assistance with a stylet. There were no complications during capsule passage. All EIGBs were visualized successfully on X-ray before and after filling. All patients were successfully discharged 2-4 h after the EIGB placement. The most common adverse events after EIGB placement were nausea and vomiting (73\% (35/48) and $50 \%(24 / 48)$ of patients, respectively). All nausea and vomiting were either self-limiting or resolved with medications (Table 1) in 2-3 days. At the end of the treatment, all EIGBs were naturally excreted in the stool.

\section{Impact of LCKD and LCD on FFM and RMR}

As shown in Table 3, patients that followed the LCKD lost less FFM and RMR at 4 months after EIGB placement than patients who followed the LCD (3.55 vs $14.3 \%, p<0.001$; 9.79 vs $11.4 \%, p<0.001$, respectively).

\section{Impact of LCKD and LCD on BW and FM}

Patients in the LCKD group lost significantly more FM at 4 months after EIGB placement than patients who followed

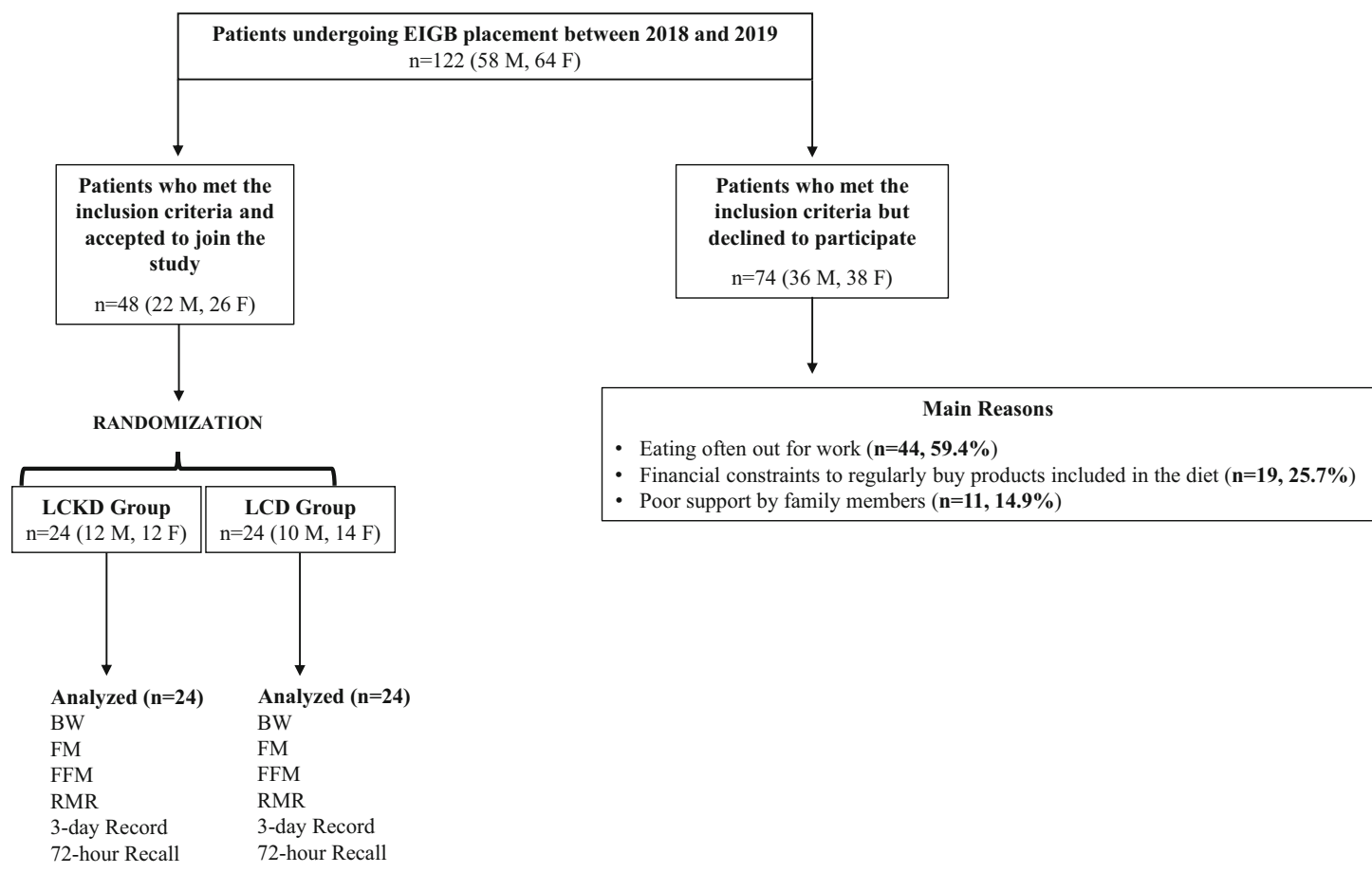

EIGB = Elipse Intragastric Balloon; $\mathbf{M}=$ Male $\mathbf{F}=$ Female $; \mathbf{V L C K D}=$ Very low calorie ketogenic diet; $\mathbf{L C D}=$ Low Calorie Diet $; \mathbf{B W}=$ Body Weight; $\mathbf{F M}=$ Fat Mass; FFM = Fat Free Mass; RMR = Resting Metabolic Rate.

Fig. 3 Flow chart of patient's selection 
Table 3 Body weight (BW), fat mass (FM), fat-free mass (FFM), resting metabolic rate (RMR), and phase angle at baseline and after EIGB (4 months). Data are reported as median (range)

\begin{tabular}{llll}
\hline Parameters & Diet & Pre-EIGB & Post-EIGB (follow-up 4 months) \\
\hline TBW (kg) & LCKD & $112(90-122)^{\mathrm{a}}$ & $91.8(72.8-100)^{\mathrm{c}}$ \\
& LCD & $106.5(98-125)$ & $84.1(77.4-98.7)^{\mathrm{c}}$ \\
FM (kg) & LCKD & $37.5(15-51.2)^{\mathrm{a}}$ & $21.9(6.9-34)^{\mathrm{c}}$ \\
& LCD & $36.2(28-44)^{\mathrm{c}}$ & $24.2(17-38.1)^{\mathrm{c}}$ \\
FFM (kg) & LCKD & $70.5(65-78)^{\mathrm{a}}$ & $68(55-75)^{\mathrm{c}}$ \\
& LCD & $70(64.7-82.5)$ & $60(48-66)^{\mathrm{c}}$ \\
RMR (kcal/day) & LCKD & $2170(1885-2456)^{\mathrm{b}}$ & $1957.5(1827-2175)^{\mathrm{c}}$ \\
& LCD & $2030(1875-2392)$ & $1798(1440-1972)^{\mathrm{c}}$ \\
Phase Angle $\left(^{\circ}\right)$ & LCKD & $7.1(5.7-7.7)^{\mathrm{a}}$ & $6.0(4.7-6.5)^{\mathrm{c}}$ \\
& LCD & $7.0(6.2-8)$ & $5.5(5.1-6.4)^{\mathrm{c}}$ \\
\hline
\end{tabular}

LCKD, low-calorie ketogenic diet

LCD, low-calorie diet

EIGB, Elipse ${ }^{\mathrm{TM}}$ intragastric balloon

${ }^{\mathrm{a}} p \geq 0.05$ vs pre-EIGB LCD

${ }^{\mathrm{b}} p<0.05$ vs pre-EIGB LCD

${ }^{\mathrm{c}} p<0.05$ vs pre-EIGB

the LCD (41.6 vs $33.1 \%, p=0.0606$, despite a significantly lower WL (18 vs $21 \%, p<0.001$, Table 3 ).

\section{Impact of LCKD and LCD on patient's Clinical Parameters}

As shown in Table 2, both LCKD and LCD patients showed a clear improvement in patients' clinical status, including liver enzyme levels (GOT, GPT, and GGT), glycemic profile (glucose and insulin), and lipid profile (total cholesterol, HDL, and LDL, and triglycerides), without detecting any significant deviation in biochemical kidney parameters (creatinine, urea, and GFR) and uric acid levels. Furthermore, after the 4-month LCKD, patients had significantly higher blood ketone levels compared to baseline $(p<0.001)$ whereas in LCD group only a not significant trace of blood ketones was found compared to baseline $(p=0.527)$ (Table 2).

\section{Three-Day Estimated Food Records vs 72-h Recalls}

No significant differences in the estimated nutrient intake were observed between the post-EIGB placement diet prescription, the 72-h recalls, and the 3-day estimated food records in both LCKD and LCD groups. Values for energy intake (expressed in $\mathrm{kcal} /$ day) and all macronutrients reported during the 72 -h recalls and the three-day estimated records were strictly similar to those of the post-EIGB placement, indicating a high patient's compliance of following the prescribed diets in both group studies (Table 4).

\section{Discussion}

Based on our findings, despite the small sample size, this study indicates that LCKD is associated with an increased FM loss while reducing the FFM loss and the RMR, without interfering with renal function after EIGB. These findings are in accordance with other studies who confirmed that the ketogenic diet is safe and highly effective in terms of BW reduction without inducing a significant FFM loss $[18,34]$.

Interestingly, herein, we found that patients who followed the LCD had a greater total body weight loss, at 4 months after EIGB, than patients who followed the LCKD. Our findings indicate that the higher weight loss in the LCD group was mainly due to FFM loss and less FM than the experimental group. The net result of the body composition changes is a greater total body weight decrease in the LCD group. Our results indicate that the process of body weight loss is more physiologic in the experimental group that loses less FFM than the control group. Among the bioimpedance parameters measured with BIA, the phase angle (defined as the ratio of resistance (intracellular and extracellular resistance) to reactance (cell membrane-specific resistance) expressed as an angle) is a clinically important parameter used for nutritional assessment and for assessment of the risk of various disease [35]. Interestingly, as shown in Table 3, herein, we found that patients who followed the LCD had a lower phase angle, at 4 months after EIGB placement, than patients who followed the LCKD. In our opinion, this finding is clinically relevant considering that the phase angle represents both the amount and quality of soft tissue, with a high phase angle reflecting 
Table 4 Macronutrients daily intake from the 3-day estimated food record and the 72-h recall of the participants consuming a low-calorie ketogenic $\operatorname{diet}(\mathrm{LCKD})$ or a low-calorie diet (LCD). $p<0.05$

\begin{tabular}{|c|c|c|c|c|}
\hline Parameter & $\begin{array}{l}\text { LCKD } \\
\text { Prescribed food plan }\end{array}$ & $\begin{array}{l}\text { 3-day estimated food record } \\
\text { Follow-up, } 4 \text { months }\end{array}$ & $\begin{array}{l}\text { 72-h recall } \\
\text { Follow-up, } 4 \text { months }\end{array}$ & $p$ \\
\hline Energy (kcal) & 1200 & $1270 \pm 41.3$ & $1250 \pm 30.9$ & 0.0637 \\
\hline Protein $(\%)$ & 25 & $28 \pm 5.3$ & $26.2 \pm 7.2$ & 0.329 \\
\hline Carbohydrate (\%) & 4 & $4.8 \pm 0.87$ & $4.6 \pm 2.4$ & 0.703 \\
\hline Fat $(\%)$ & 71 & $67.2 \pm 15.2$ & $69.2 \pm 21.8$ & 0.714 \\
\hline Energy (kcal) & 1200 & $1235 \pm 31.9$ & $1255 \pm 46.3$ & 0.0881 \\
\hline Protein $(\%)$ & 43 & $48 \pm 10.4$ & $46.2 \pm 17.2$ & 0.663 \\
\hline Carbohydrate (\%) & 40 & $43.7 \pm 20.3$ & $45.4 \pm 22.9$ & 0.787 \\
\hline Fat $(\%)$ & 15 & $8.3 \pm 3.5$ & $8.4 \pm 2.8$ & 0.913 \\
\hline
\end{tabular}

higher cellularity, better cell heath and better nutritional status [35].

Furthermore, the sustained weight and FM loss induced by LCKD did not induce any significant reduction in RMR, probably due to the preservation of FFM. In particular, we show that in the LCKD group, the RMR was preserved and remained within the expected limits for the variation in FFM. Interestingly, the metabolic adaptation phenomenon called "adaptative thermogenesis," defined as a decrease in RMR out of proportion to the decrease in body mass was not activated in concomitance with the LCKD [20, 36, 37]. On the contrary, patients in the LCD group in addition to the significant weight and FM loss showed a significant decrease in both FFM and RMR.

RMR is recognized as the major component of total energy expenditure, being responsible for about $75 \%$ of daily total energy expenditure [38]. Therefore, any RMR reductioninduced WL translates into a large impact on energy balance, making subjects more prone to weight regain over time [12, 20]. In agreement with Gomez-Arbelaez et al., herein, we found that the most plausible reason accounting for the not significant reduction of RMR seen in patients who had the LCKD after the EIGB is the preservation of FFM [20]. Preservation of initial RMR after WL could play a key role in preventing weight regain in the short and long time [39].

In the present study, we found that before EIGB placement, RMR was slightly but significantly higher in the LCKD group than that in the LCD group. However, this data is expected because despite the fact that it is widely accepted that FFM is the major factor determining RMR [40], other factors, such as hormonal status and age, influence the RMR [40].

LCKD appears to be protective against muscle mass catabolism for at least three reasons: first, low blood sugar's level inhibits the muscle proteolysis; secondary, ketone bodies suppress the use of protein-derived amino acid by muscle; third, the $\beta$-hydroxybutyrate (the main ketone body produced during the ketogenesis process) promotes protein synthesis $[18$, 41, 42].
We also found that patients were compliant with the diet protocol based on consistent weight loss and presence of ketonuria in accordance with other studies that attended weight loss with LCKD [43-46].

Traditionally considered high protein, ketogenic diets are often looked at with concern by clinicians due to the potential harm they pose to renal function. Herein, as reported in a recent meta-analysis of Castellana et al [47], we found that LCKD appears safe, considering that not only is it associated to an important improvement in patient's clinical status but also does not affect renal function.

In the present study, body composition was measured by BIA. We are aware that BIA in severely obese patients has been criticized because of the altered electrical properties in body tissues, which may result in an overestimation of FFM and an underestimation of FM [27, 28]. However, several studies conducted in patients with obesity validate the use of BIA for the measure of body composition [25, 48-53]. Achamrah et al., in a retrospective study on 3655 subjects (653 males, 3002 females) with a body mass index (BMI) ranging from 16 to $\geq 40$, found that values of FM and FFM obtained by BIA and DXA were strongly correlated (Pearson's correlation, $r=0.95, p<0.0001$, and $r=0.89$, $p<0.0001$, respectively) [48]. Furthermore, Faria et al. in a cross-sectional validation study with 73 patients invited to undergo a multi-frequency BIA and afterwards a DXA examination found an almost perfect correlation of FM and FFM (ICC $=0.832$ and ICC $=0.899$, respectively) [51].

We acknowledge some methodological limitations of our study. First, despite after discharge the physical activity was encouraged, we were not able to directly measure it. Furthermore, FM and FFM were only measured by BIA and were not supplemented with additional and more accurate comparative measures, such as X-ray absorptiometry (DXA) or air displacement plethysmography (ADP) computed tomography (CT). However, Gomez-Arbelaez et al. recently assessed the LCKD-induced changes in body composition of patients with obesity by comparing DXA, BIA, and ADP to 
evaluate those changes [19]. In this study, similarly to the present research, twenty obese patients followed a VLCK diet for 4 months. After 4 months, the VLCK diet induced a $20.2 \pm 4.5 \mathrm{-kg}$ weight loss, at expenses of reductions in fat mass (FM) of $-16.5 \pm 5.1 \mathrm{~kg}$ (DXA), $-18.2 \pm 5.8 \mathrm{~kg}$ (MFBIA), and $-17.7 \pm 9.9 \mathrm{~kg}$ (ADP). They conclude that a strong correlation was evidenced between the 3 methods of assessing body composition, and that of the 3 body composition techniques used, the MF-BIA method seems to be more convenient in the clinical setting [19].

Nevertheless, DXA requires specialized radiology equipment and is expensive, and thus hardly feasible in routine clinical practice, whereas $\mathrm{CT}$ scan is not cost-effective and radiation exposure would not be acceptable for ethical issues. Therefore, despite the fact that we are aware that BIA, DXA, and $\mathrm{CT}$ scan methods cannot be considered interchangeable, if the systematic error associated to the measurements of BIA is accepted, the latter remains a simple, safe, non-invasive, and low-cost method for FM and FFM assessment in clinical practice and research studies also in the setting of obesity [25, 48-53].

\section{Conclusion}

This prospective, randomized, controlled trial shows, despite the small sample size, that in patients undergoing EIGB, LCKD is associated with an increased FM loss while reducing the FFM loss and the RMR, without interfering with renal function when compared with LCD. Further and larger randomized clinical trials are needed to confirm these preliminary data.

\section{Compliance with Ethical Standards}

Conflict of Interest The authors declare that they have no conflicts of interest.

Ethical Approval All procedures performed in this study were in accordance with the ethical standards of the institutional and/or national research committee and with the 1964 Declaration of Helsinki and its later amendments or comparable ethical standards. Research Registry Unique Identifying Number 5478.

Informed Consent Informed consent was obtained from all individual participants included in the study.

Open Access This article is licensed under a Creative Commons Attribution 4.0 International License, which permits use, sharing, adaptation, distribution and reproduction in any medium or format, as long as you give appropriate credit to the original author(s) and the source, provide a link to the Creative Commons licence, and indicate if changes were made. The images or other third party material in this article are included in the article's Creative Commons licence, unless indicated otherwise in a credit line to the material. If material is not included in the article's Creative Commons licence and your intended use is not permitted by statutory regulation or exceeds the permitted use, you will need to obtain permission directly from the copyright holder. To view a copy of this licence, visit http://creativecommons.org/licenses/by/4.0/.

\section{References}

1. Raftopoulos I, Giannakou A. The Elipse balloon, a swallowable gastric balloon for weight loss not requiring sedation, anesthesia or endoscopy: a pilot study with 12-month outcomes. Surg Obes Relat Dis. 2017;13(7):1174-82.

2. Alsabah S, Al Haddad E, Ekrouf S, et al. The safety and efficacy of the procedureless intragastric balloon. Surg Obes Relat Dis. 2018;14(3):311-7.

3. Machytka E, Gaur S, Chuttani R, et al. Elipse, the first procedureless gastric balloon for weight loss: a prospective, observational, open-label, multicenter study. Endoscopy. 2017;49(2): $154-60$.

4. Jamal MH, Almutairi R, Elabd R, et al. The safety and efficacy of procedureless gastric balloon: a study examining the effect of Elipse intragastric balloon safety, short and medium term effects on weight loss with 1-year follow-up post-removal. Obes Surg. 2019;29(4): $1236-41$.

5. Genco A, Ernesti I, Ienca R, et al. Safety and efficacy of a new swallowable intragastric balloon not needing endoscopy: early Italian experience. Obes Surg. 2018;28(2):405-9.

6. Genco A, Ernesti I, Ienca R, et al. safety and efficacy of a new swallowable intragastric balloon not needing endoscopy: early Italian experience. Obes Surg. 2018;28(2):405-9.

7. Wolfe RR. The underappreciated role of muscle in health and disease. Am J Clin Nutr. 2006;84(3):475-82.

8. Schiavo L, Scalera G, Sergio R, et al. Clinical impact of Mediterranean-enriched-protein diet on liver size, visceral fat, fat mass, and fat-free mass in patients undergoing sleeve gastrectomy. Surg Obes Relat Dis. 2015 Sep-Oct;11(5):1164-70.

9. Schiavo L, Scalera G, Pilone V, et al. Fat mass, fat-free mass, and resting metabolic rate in weight-stable sleeve gastrectomy patients compared with weight-stable nonoperated patients. Surg Obes Relat Dis. 2017 Oct;13(10):1692-9.

10. Schiavo L, Scalera G, Pilone V, et al. Preservation of fat-free mass after bariatric surgery: our point of view. Obes Surg. 2017;27(4): 1071-3.

11. Schiavo L, Scalera G, Pilone V, et al. Comparative study examining the impact of a protein-enriched vs normal protein postoperative diet on body composition and resting metabolic rate in obese patients after sleeve gastrectomy. Obes Surg. 2017;27(4):881-8.

12. Ravussin E, Lillioja S, Knowler WC, et al. Reduced rate of energy expenditure as a risk factor for body-weight gain. N Engl J Med. 1988;318(8):467-72.

13. Al-Khalifa A, Mathew TC, Al-Zaid NS, et al. Therapeutic role of low-carbohydrate ketogenic diet in diabetes. Nutrition. 2009;25(11-12):1177-85.

14. Dashti HM, Mathew TC, Khadada M, et al. Beneficial effects of ketogenic diet in obese diabetic subjects. Mol Cell Biochem. 2007;302(1-2):249-56.

15. Brehm BJ, Seeley RJ, Daniels SR, et al. A randomized trial comparing a very low carbohydrate diet and a calorie-restricted low-fat diet on body weight and cardiovascular risk factors in healthy women. J Clin Endocrinol Metab. 2003;88(4):1617-23.

16. Pilone V, Tramontano S, Renzulli M, et al. Metabolic effects, safety, and acceptability of very low-calorie ketogenic dietetic scheme on candidates for bariatric surgery. Surg Obes Relat Dis. 2018;14(7):1013-9.

17. Schiavo L, Pilone V, Rossetti G, et al. A 4-week preoperative ketogenic micronutrient-enriched diet is effective in reducing body weight, left hepatic lobe volume, and micronutrient deficiencies in 
patients undergoing bariatric surgery: a prospective pilot study. Obes Surg. 2018;28(8):2215-24.

18. Rondanelli M, Faliva MA, Gasparri C, et al. Current opinion on dietary advice in order to preserve fat-free mass during a lowcalorie diet. Nutrition. 2020;72:110667.

19. Gomez-Arbelaez D, Bellido D, Castro AI, et al. Body composition changes after very-low-calorie ketogenic diet in obesity evaluated by 3 standardized methods. J Clin Endocrinol Metab. 2017;102(2): 488-98.

20. Gomez-Arbelaez D, Crujeiras AB, Castro AI, et al. Resting metabolic rate of obese patients under very low-calorie ketogenic diet. Nutr Metab (Lond). 2018;15:18.

21. Machytka E, Chuttani R, Bojkova M, et al. Elipse ${ }^{\mathrm{TM}}$, a procedureless gastric balloon for weight loss: a proof-of-concept pilot study. Obes Surg. 2016;26(3):512-6.

22. Choi SJ, Choi HS. Various intragastric balloons under clinical investigation. Clin Endosc. 2018;51(5):407-15.

23. Efird J. Blocked randomization with randomly selected block sizes. Int J Environ Res Public Health. 2011;8(1):15-20.

24. Albanese A, Prevedello L, Markovich M, et al. Pre-operative very low-calorie ketogenic diet (VLCKD) vs. very low calorie diet (VLCD): surgical impact. Obes Surg. 2019;29(1):292-6.

25. Schiavo L, Pilone V, Tramontano S, Rossetti G, Iannelli A. May bioelectrical impedance analysis method be used in alternative to the dual-energy X-ray absorptiometry in the assessment of fat mass and fat free mass in patients with obesity? Pros, cons and perspectives. Obes Surg 2020;00(0):00-00

26. Haugen HA, Chan LN, Li F. Indirect calorimetry: a practical guide for clinicians. Nutr Clin Pract. 2007;22(4):377-88.

27. Nieman DC, Austin MD, Benezra L, et al. Validation of Cosmed's FitMate in measuring oxygen consumption and estimating resting metabolic rate. Res Sports Med. 2006;14(2):89-96.

28. Haugen HA, Melanson EL, Tran ZV, et al. Variability of measured resting metabolic rate. Am J Clin Nutr. 2003;78(6):1141-5.

29. Compher C, Frankenfield D, Keim N, et al. Evidence Analysis Working Group. Best practice methods to apply to measurement of resting metabolic rate in adults: a systematic review. J Am Diet Assoc. 2006;106(6):881-903.

30. Hsu CY, Bansal N. Measured GFR as "gold standard"-all that glitters is not gold? Clin J Am Soc Nephrol. 2011;6(8):1813-4.

31. Schröder H, Covas MI, Marrugat J, et al. Use of a three-day estimated food record, a 72-hour recall and a food-frequency questionnaire for dietary assessment in a Mediterranean Spanish population. Clin Nutr. 2001 Oct;20(5):429-37.

32. Schiavo L, Scalera G, Pilone V, et al. Micronutrient deficiencies in patients candidate for bariatric surgery: a prospective, preoperative trial of screening, diagnosis, and treatment. Int J Vitam Nutr Res. 2015 Dec;85(5-6):340-7.

33. Schiavo L, Pilone V, Rossetti G, et al. Correcting micronutrient deficiencies before sleeve gastrectomy may be useful in preventing early postoperative micronutrient deficiencies. Int J Vitam Nutr Res. 2019 Jul;89(1-2):22-8.

34. Merra G, Miranda R, Barrucco S, et al. Very-low-calorie ketogenic diet with aminoacid supplement versus very low restricted-calorie diet for preserving muscle mass during weight loss: a pilot doubleblind study. Eur Rev Med Pharmacol Sci. 2016;20(12):2613-21.

35. Tanaka S, Ando K, Kobayashi K, et al. Low bioelectrical impedance phase angle is a significant risk factor for frailty. Biomed Res Int. 2019 Jun 10;2019:6283153.

36. Galgani JE, Santos JL. Insights about weight loss-induced metabolic adaptation. Obesity (Silver Spring). 2016;24(2):277-8.
37. Müller MJ, Bosy-Westphal A. Adaptive thermogenesis with weight loss in humans. Obesity (Silver Spring). 2013;21(2):218-28.

38. Ravussin E, Lillioja S, Anderson TE, et al. Determinants of 24-hour energy expenditure in man. Methods and results using a respiratory chamber. J Clin Invest. 1986;78(6):1568-78.

39. Fothergill E, Guo J, Howard L, et al. Persistent metabolic adaptation 6 years after "The Biggest Loser" competition. Obesity (Silver Spring). 2016;24(8):1612-9.

40. Johnstone AM, Murison SD, Duncan JS, et al. Factors influencing variation in basal metabolic rate include fat-free mass, fat mass, age, and circulating thyroxine but not sex, circulating leptin, or triiodothyronine. Am J Clin Nutr. 2005;82(5):941-8.

41. Manninen AH. Very-low-carbohydrate diets and preservation of muscle mass. Nutr Metab (Lond). 2006 Jan 31; 3:9.

42. Paoli A, Canato M, Toniolo L, et al. The ketogenic diet: an underappreciated therapeutic option? Clin Ter. 2011;162(5):e145-53.

43. Leonetti F, Campanile FC, Coccia F, et al. Very low-carbohydrate ketogenic diet before bariatric surgery: prospective evaluation of a sequential diet. Obes Surg. 2015 Jan;25(1):64-71.

44. Paoli A, Rubini A, Volek JS, et al. Beyond weight loss: a review of the therapeutic uses of very-low-carbohydrate (ketogenic) diets. Eur J Clin Nutr. 2013 Aug;67(8):789-96.

45. Veech RL. The therapeutic implications of ketone bodies: the effects of ketone bodies in pathological conditions: ketosis, ketogenic diet, redox states, insulin resistance, and mitochondrial metabolism. Prostaglandins Leukot Essent Fat Acids. 2004 Mar;70(3):309-19.

46. Cappello G, Franceschelli A, Cappello A, et al. Weight loss and body composition changes following three sequential cycles of ketogenic enteral nutrition. J Res Med Sci. 2012 Dec;17(12):1114-8.

47. Castellana M, Conte E, Cignarelli A, et al. Efficacy and safety of very low-calorie ketogenic diet (VLCKD) in patients with overweight and obesity: a systematic review and meta-analysis. Rev Endocr Metab Disord. 2020;21(1):5-16.

48. Achamrah N, Colange G, Delay J, et al. Comparison of body composition assessment by DXA and BIA according to the body mass index: a retrospective study on 3655 measures. PLoS One. 2018 Jul 12;13(7):e0200465.

49. Ellegård L, Bertz F, Winkvist A, et al. Body composition in overweight and obese women postpartum: bioimpedance methods validated by dual energy X-ray absorptiometry and doubly labeled water. Eur J Clin Nutr. 2016;70(10):1181-8.

50. Pateyjohns IR, Brinkworth GD, Buckley JD, et al. Comparison of three bioelectrical impedance methods with DXA in overweight and obese men. Obesity (Silver Spring). 2006 Nov;14(11):206470.

51. Faria SL, Faria OP, Cardeal MD, et al. Validation study of multifrequency bioelectrical impedance with dual-energy X-ray absorptiometry among obese patients. Obes Surg. 2014;24(9):1476-80.

52. Panotopoulos G, Ruiz JC, Guy-Grand B, et al. Dual x-ray absorptiometry, bioelectrical impedance, and near infrared interactance in obese women. Med Sci Sports Exerc. 2001;33(4):665-70.

53. Ballesteros-Pomar MD, Calleja-Fernández A, Diez-Rodríguez R, et al. Comparison of different body composition measurements in severely obese patients in the clinical setting. Nutr Hosp. 2012;27(5):1626-30.

Publisher's Note Springer Nature remains neutral with regard to jurisdictional claims in published maps and institutional affiliations. 